\title{
Towards More Sustainability: A Dynamic Recycling Framework of Discarded Products Based on SD Theory
}

\author{
Xia De \\ School of Management, Wuhan University of Technology, Wuhan, P.R.China, 430070 \\ Email:xiadetiger@126.com \\ Fangru $\mathrm{Wu}$ \\ School of Management, Wuhan University of Technology, Wuhan, P.R.China, 430070 \\ Email:alicia0710@163.com
}

\begin{abstract}
The mechanism of a recycling system about discarded products is running with a few critical roles and processes. To identify the relationship and collaborate the activities involved in this recycling circle are the very significant work in practice. For the sake the paper explores and identifies the critical drivers underlying the system, based on which a framework is established to explore the relationship among relevant activities consisted of collection, remanufacturing and resale, as well as companies and customers' behaviours. A dynamic quantitative model is designed to simulate this vigorous relation, which demonstrates and verifies the rule of this relationship with details about the recycling activities. The information will benefit practitioners a lot in terms of the recycling operation planning under different situation.
\end{abstract}

Index Terms: System Dynamics, Recycling, Discarded Product, Collection

\section{INTRODUCTION}

The experience and research on remanufacturing of discarded products have attracted great efforts of business and academic field. Many articles are published on the sorting, recycling and processing methods. Overviews are provided by Fleischmann et al. [1], Guide et al. [2], and Gupta and Gungor [3]. For a discussion of more recent results we refer readers to Dekker et al. [4].Theses researches show that it is necessary to design different procedures and methods based on the categories of discarded products. Meanwhile some academic researches innovate view of closed supply chain to integrate foreword and backward processes (Rogers, D., TibbenLembke, R.[5]). Resale as well as collection and remanufacturing, is a critical activity composing the closed recycling loop. Generally remanufacturing composites of disassembly, cleaning, testing, part replacement/repair, and reassembly operations (Guide et a [2]), after which they are as-good-as-new. The latter term distinguishes remanufacturing from other recovery types such as material and energy recycling. Products that are nowadays remanufactured include single use cameras, machine tools, medical instruments, copiers, automobile engines, computers, aviation equipment, telephone equipment, and tires. The researches of Sprow[6], K. Richter and M. Sombrutzki[7] show that the initiative of customers and enterprises is the essential factor affecting the remanufacturing operation in closed supply chain. And behaving habits of these customers and companies are shaped by environmental legislation, societal pressure, and economic opportunities, especially over the past decades(Patroklos Georgiadis , Dimitrios Vlachos[8], Taylor, H. [9]).

To explore the relationship among the activities and participants, system dynamic (SD) methodology is a significant measurement, which is applied in this work. SD was introduced by Forrester [10] in the early 1960s as a modelling and simulation methodology for analysis and long term decision making in dynamic industrial management problems. Since then, SD has been applied to various business policy and strategy problems [11,12]. There are already some publications using SD in supply chain modelling, but most of them refer to forward logistics. Towill [13] uses SD in supply chain redesign to generate added insight into system dynamics behaviour and particularly into underlying casual relationships. The outputs of the proposed model are industrial dynamics models of supply chains. Minegishi and Thiel [14] use SD to improve the knowledge of the complex logistic behaviour of an integrated food industry. They present a generic model and some practical simulation results applied to the field of poultry production and processing. Sterman [12] presents two case studies where SD methodology is used to model reverse logistics problems. In the first one, Zamudio-Ramirez [15] analyses part recovery and material recycling in the US auto industry to assist the industry think about the future of enhanced auto recycling. In the second one, Taylor [9] concentrates on the market mechanisms of paper recycling, which usually lead to instability and inefficiency in flows, prices, etc. A notable work is the research of Patroklos Georgiadis and Dimitrios Vlachos[8], which analyses the effect of environmental parameters on product recovery while SD methodology is applies. 
This work focuses on correlation among relevant participants and their behaviours in collection, remanufacturing and resale of products discarded.

In this work we just focus on discarded product which can be remanufactured. Generally they are end of use products and end of life products with considerable surplus function. End of life products are ones which loss their original function partly because of damage or fashion. But there are still a few parts and components with surplus function which can be utilized to assemble new products. End of use product even may be better function situation after accomplishment of certain tasks for a customer. So the products can be remanufactured or refurnished easily, especially in rent business. Many containers, medical facility and book are good examples.

The essay is arranged as follows. In the section 2 the driving forces in recycling system is analyzed. Then the two critical drivers and their behaviours in this system are studied in the section 3. Based on theses analysis a dynamic analysis framework is shaped to explore the relation among participants and recycling processes in the section 4. The fifth section establishes a quantitative model to analyse the relationship of dynamic recycling processes. In section 6 the simulation of the model is applied while the results are analysed. At the end of this essay a conclusion of the work is made in terms of the strengths and weak of this dynamic recycling model.

\section{ANALYSIS OF DRIVING FORCE IN RECYCLING SYSTEM}

To ensure products recycled properly it is necessary to identified internal driving engine in the system. Based on previous research the driving force comes from three resources[8][9]. They are direct and indirect economical benefit, law and regulation, responsibility and consciousness on environment.

\section{A. Economical driver}

Direct economical driver includes saving on cost of materials and parts, value-added during recycling procedures. Meanwhile there are some essential indirect benefit, such as market protection, environmental friendly image and improved relationship with suppliers and customers.

\section{B. Obligation resulted from law and regulation}

There are increasing number countries that require OEM and suppliers to provide reasonable solution for future discarded products when they introduce endproducts to certain market. Even average customers do bear certain similar obligation. They are encouraged to take part in the recycling activities, such as collection, sorting and delivery of discarded products.

\section{Responsibility of customers and organizations with environmental consciousness}

While customers benefit from the consumption of goods they are also comply with morale code to protect environment. Organizations also bear social responsibility while shaping their positive public image.

\section{EXPLOITATION OF TWO PARTICIPANTS IN RECYCLING PROCESSES}

As mentioned above there are many factors influence the recycling processes. Many of these factors are decided by two participants directly, customers and related companies. Their behaving habit and initiative on recycling processes are critical to perfect recycling system.

Customer behaviour is affected by several forces. Firstly allowances on price and compulsory task are common to adjust customers' habits on discarded products, especially in short term and in underdeveloped region. But for a long term it is education and advertisement that produce continuous dynamic driver to ensure customers to shape good habits as expectation. These forces are similarity in the end that converts customers, who are ignorance and abuse discarded products, into reasonable ones with strong environmental consciousness. And these customers, in other word, people with environmental consciousness (PEC) will take part in the recycling activities initiatively, such as to collection, sorting and delivery used products. The transformation of customers' habit decides the collection ratio of discarded products.

For companies and organizations involved recycling system, the similar transformation is driven mainly by economical benefit and law. It is resulted from either legal allowance or intensive demands of remanufactured products from market. The influence of law and regulation are substantial. Once discarded products enter the recycling supply chain, the following remanufacturing processes, such as collection, sorting and refurbishing, are pushed forward by the initiative of companies for revenues. If there are considerable orders and positive reflection on remanufactured products from market, the companies will take great efforts to recycling processes which would lead to increasing a collection ratio and higher productivity. 


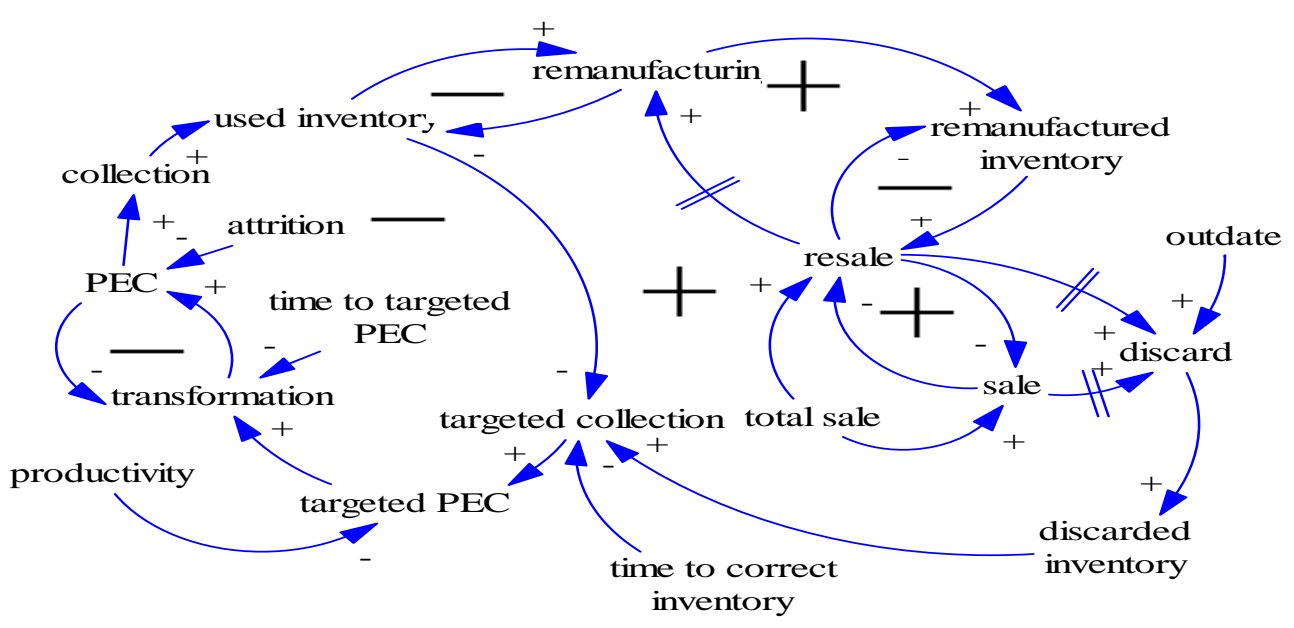

Figure.1 Dynamic framework of recycling business on discarded products

\section{DYNAMIC ANALYSIS OF RECYCLING PROCESSES}

The recycling business shown in Figure. 1 focuses on a few significant contents and processes.

\section{A. Obsolescence and collection of products}

The current products in a market become obsolete at certain ratio, which depends on the technology innovation and evolution of demand tendency. Then products discarded are collected, which supported by customers, companies and relevant organizations because of three driver forces mentioned above.

Economical driver results from the market reflection. Customers accept and recognize the high cost-function remanufactured products, which leads to intensive demands and encourages relevant companies to take part in the recycling activities more initiatively and efficiently. The reaction-chain is the positive and continuous force which decides the operation of recycling system. At the beginning establishment of relative law and regulation may lead behaviours of customers and companies into a right track. But this governing methodology would like lead to unacceptable cost resulted from rigour administrative monitor in the whole life of every product. So to awake environmental consciousness through intensive education system is a good complementary measurement to adjust relative behaviours on discarded products through.

\section{B. Remanufacturing and resale}

The quality of remanufactured products should be identical to entire new ones. While it is common that quality status is various when discarded products arrive collecting centres. So remanufacturing for resale may happen at different level of discarded products. Recovery is needed for whole products, while renewing happens at modular level for upgrade. In some cases refurbishment at component level with dismantlement and assembly is necessary as well as selective repair at part level for reassembly. And there is no difference on end-product quality among various process methods. The rest of discarded products will be recycled as raw materials through destructive way, such as shredding and smelting. This paper focuses on the non-destructive way to remanufacturing discarded products.

For products renewed there are several different categories of customers preference on products. Firstly there is no discrimination on price when customers encounter entire new products and products renewed. For example some medical facilities returned are sold or rented as same as entire ones after through entire disinfection. Theses reusing processes from production to collection will lead to perfect closed recycle loop. On the other hand products renewed and entire new products meet different customers respectively. In practice there are many reasons for the difference, such as unbalance of development on economy, education and fashion, which may increases the uncertainty of demands on products renewed. But reaction on products renewed from customers influences stably companies' initiative to take part in the recycling activities. Intensive demands on renewed products will trigger relevant companies' positive reaction because of considerable revenue generated from recycling business.

\section{Situation and transformation of recycling system}

The link of situation and transformation of products recycled and customers' behaviours are the focuses of this dynamic recycling mechanism.

Recycling system changes its situation at every stage along the operational process cycle while products change their forms. The sum of current using products and demands are the up bound of perspective recyclable products. Supposedly the out-date ratio of certain products is relative stable, the quantity of discarded products can be forecasted reasonably, which will be the goal of future recycling business. Products out-dated will pool into inventory of discarded products after they are collected by customers and companies. The level of the inventory is decided by collection ratio of collectors and order ratio of remanufacturing. Then outcome of remanufacturing process will build inventory of renewed products waiting for shipment based on order from customers. The inventory volume of renewed products is function of remanufacturing productivity and order ratio 
from customers. While inventory volume at every stagy illustrates the result of product situation quantitatively, the transforming ratios, which reflects the speed of products from one stage to another, reflect the tendency of customers' and companies' attitudes and behaviours on used products. Ultimately customers' attitudes on discarded products and consumption of renewed products decide the situation of recycling business.

So the situation of customers' behaviours and attitudes is an important issue to be explored. Efficient collection of discarded products, which is the beginning of successful recycling system, is mainly decided by customers who produce them directly. With strong environmental consciousness there will be great difference on customers' performance in the collecting process including accumulation, sorting and delivery. Otherwise customer will ignore and abuse used products which lead to serious environment problem. So it is essential to transform customers from environmental ignorance into strong environmental protectors. The successful conversion of customers not only ensures a reasonable collection ratio but also encourages them to order renewed products. The increasing order of renewed products may trigger relevant companies' positive reaction to collect and produce more renewed products. Economical driver will ensure an optimized recycling system. On the other hand, practically while many customers are converted into the group with environmental consciousness some may quit for reasons. For example, the design failure of relevant regulations, unfair distribution of revenues and misunderstanding may offend customer to behave adversely. It is definite that theses factors, regulations, revenues and moral obligation, influence orientation of customers' behaviours on environment.

\section{V.ESTABLISHMENT OF SD MODEL}

\section{A. Quantitative dynamic system}

In the dynamic recycling system above there are several categories of parameters. They illustrate and measure the situation of elements in the recycling system, including collection, manufacturing, inventory, order, obsolescence as well as customer group with environmental consciousness. These elements are clarified by either their transformation process or inventory with ratio and level respectively.

Products in use are the resources to be collected, and decide the available quantity of discarded product along with collection ratio and out-dated ratio. Remanufacturing ratio decides the inventory of renewed products which will shrink based on order from customers. The closed recycling system can be shown as Figur.2 based on Dynamic System theory.

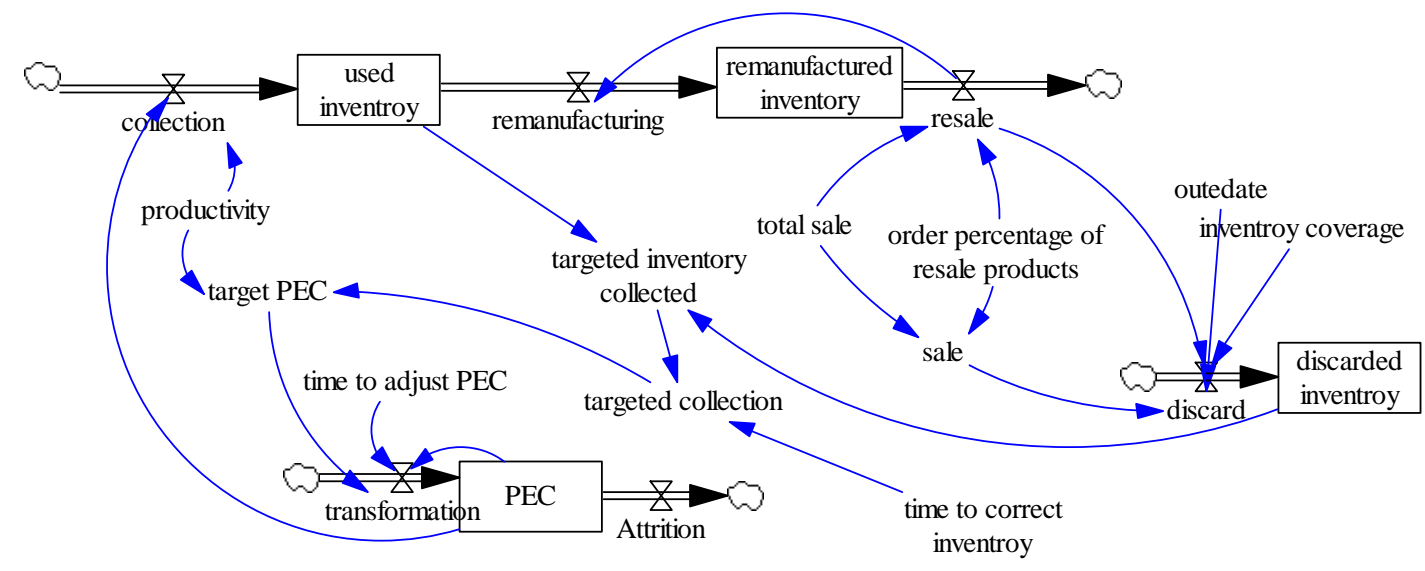

Figure 2 The dynamic simulation model of a recycling system

\section{B. variables and equations of the quantitative modelling system}

According to the flow structure in figure 2, there are group of parameter as follows for the quantitatively analysis.

\section{(1)Variables of rate and level}

$R_{\text {collection }}$ : collection ratio

$R_{\text {remanufacturing }}$ : remanufacturing of used products

$R_{\text {resale }}$ :resale of remanufactured product

$R_{\text {discarded }}$ : discarding of product
$R_{t}$ :transformation of people into ones with

environmental consciousness

$R_{\text {attrition }}:$ attrition ratio

\section{(2)Level of variable}

$L_{i}^{\text {used }}$ :inventory

$L_{i}^{\text {refur }}$ :inventory of remanufactured products

$L_{i}^{\text {discarded }}$ :desired inventory

$L_{P E C}$ : people with environment consciousness 


\section{(3)Auxiliary variables and constants}

$V_{\text {targeted-inventory-collected }}$ :targeted inventory of outdate product

$V_{t \text { argetedcollection }}:$ targeted collection of outdate product

$V_{t \text { argetedPEC }}:$ targeted number of people with environmental consciousness

$V_{\text {sale }}$ :sale of entire new product

$\beta$ : Order percentage of secondary products in total demand

$\alpha$ : Remanufacturing ratio.

\section{(4)Constant in system}

$C_{\text {totalsale }}$ :total sale of products

$C_{\text {coverage }}$ : inventory coverage

$C_{\text {outdate }}$ : outdate ratio of product

$C_{\text {productivity }}$ : Productivity of no useful product per person

\section{(5)Time constant}

$T_{\text {time-to-correctinventroy }}:$ time to correct inventory

$T_{\text {time-to-adjustedpec }}$ :time to adjust PEC

According to the analysis above there are some equations and polynomials as following.

$$
\begin{aligned}
& L_{i}^{\text {used }}=\int_{s}^{t}\left[R_{\text {collection }}(t)-R_{\text {remanufacturing }}(t)\right] d(t) \\
& L_{i}^{\text {refur }}=\int_{s}^{t}\left[R_{\text {remanufacturing }}(t)-R_{\text {resale }}(t)\right] d(t) \\
& L_{i}^{\text {discarded }}=\int_{s}^{t}\left[R_{\text {discarded }}(t)\right] d(t) \\
& L_{\text {pec }}=\int_{s}^{t}\left[R_{t}(t)-R_{\text {attrition }}(t)\right] d(t) \\
& R_{\text {collection }}=L_{\text {pec }} * C_{\text {productivity }} \\
& R_{\text {remanufacturing }}=D_{\text {Delay }}\left(R_{\text {resale }}\right) \\
& R_{\text {resale }}=C_{\text {totalsale }} * \beta \\
& R_{\text {discarded }}=\left(R_{\text {resale }}+V_{\text {sale }}\right) * C_{\text {outdate }} * C_{\text {coverage }}
\end{aligned}
$$

$$
R_{t}=\left(V_{\text {targetedpec }}-L_{\text {pec }}\right) / T_{\text {time-to-adjustedpec }}
$$$$
V_{\text {targeted-inventroy-collected }}=L_{i}^{\text {discarded }}-L_{i}^{\text {used }}
$$

$V_{\text {targetedcollection }}=V_{\text {targeted-inventroy-collected }} / T_{\text {time-to-correctinventory }}$

$V_{\text {targetedpec }}=V_{\text {targetedcollection }} / C_{\text {productivity }}$

$\beta=\Phi(t), t \in($ starttime, final)

$\alpha=\Gamma(t), t \in($ starttime, final $)$

$C_{\text {totalsale }}=100$

$C_{\text {coverage }}=5$

$C_{\text {outdate }}=0.89$

$C_{\text {productivity }}=2$

$T_{\text {time-to-correctinventory }}=20$

$T_{\text {time-to-adjustedpec }}=15$

$R_{o} \leq R_{r}$

$R_{r} \leq R_{c}$

$R_{c} \leq C_{\text {or }}$

$\beta=\Phi(t) \leq 1$

$\alpha=\Gamma(t) \leq 1$

$0 \leq \Gamma^{\prime}(t) \leq \Phi^{\prime}(t)$

$\gamma=\Psi(t) \leq 1$

$\Gamma^{\prime \prime}(t), \Psi^{\prime \prime}(t), \Phi^{\prime \prime}(t) \leq 0$

$0 \leq \Gamma^{\prime}(t) \leq \Psi^{\prime}(t) \leq \Phi^{\prime}(t)$

\section{Analysis of parameters for different situation}

Firstly demand from market is satisfied by renewed products and entire new products. In other words, the secondary market will be identical to entire new one when there is no difference between customer's choice on new products and renewed products (such as certain medical appliance). Under this situation the total demands of certain products are stable, as $C_{d}$. The demand volume of renewed products can be denoted as $R_{o}=C_{d *} \beta$. The rest, $C_{d}$ (1- $\beta$ ), will be the entire new products entering the recycling system. Supposedly during recycling process there will be some products dropped out because of wear out. So discarded products collected are 
refurbished partly, and there will be $R_{r} \leqslant R_{c * \alpha}$. In this case the levels of $\beta$ and $\alpha$ are stable and constants.

But at some occasion customers discriminate renewed products and entire new one. There is different quality between two markets. Consumptions tendency will be influenced by transformation of customer behaviours, which will lead to unstable initiative of relevant customers as changeable demands on renewed products.

Customers adjust their consumption behaviours because of positive influence resulted from three driving forces mentioned above. They prefer renewed products rather entire new ones. For this reason order percentage of secondary products in total demand $(\beta$ ) would be an increasing function of time as $\beta=\Phi(t) \leq 1$. It is reasonable to set up bound of demands met by renewed products as $C_{d *} \beta \leq R_{r}$.

Hypothetically the recycled product can be reused for several times before they drop out the recycling system and are collected as raw materials and energy. The remanufacturing ratio $\left(R_{r}\right)$ function as the dropping out switch. Meanwhile remanufacturing ratio ( $R_{r}$ ) $R_{r} \leq R_{c} * \alpha$ narrates other story. The initiative of company involved recycling system is affected by social responsibility and demands from customers. If there is increasing positive force among three drivers the companies will take efforts to improve the remanufacturing ratio $\alpha$, then $\alpha=\Gamma(t) \leq 1$ as increasing function. In practice the passive adjustment of remanufacturing ratio will postpone change of demands from customers. So there are formulas, $\Gamma^{\prime}(t) \leq \Phi^{\prime}(t)$ and $R_{r} \leq R_{c}$. As time goes by the sensitive of customers and companies on three drivers will fade so there are $\Gamma^{\prime \prime}(t), \Phi^{\prime \prime}(t) \leq 0$. When it comes to collection ratio, there is a similar situation, and can be presented as $R_{c}=C_{d} * C_{o r} \Psi(t), \gamma=\Psi(t) \leq 1$, what's more, $0 \leq \Gamma^{\prime}(t) \leq \Psi^{\prime}(t) \leq \Phi^{\prime}(t)$.

\section{SIMULATION OF DYNAMIC RECYCLING AND TRANSFORMATION SYSTEM}

\section{A.Collection rate and the level of people with environmental consciousness}

The results in Figure 3(a) show that the collection rate of discarded products has the same tendency of the level of people with environmental consciousness (PEC). It also indicates that the number of PEC will stabilize at a certain level in the coming future, at about the $450^{\text {th }}$ week. As a result the collection of discarded products delays but follows the tendency to decrease the swing and stabilize at about 480 units per week. The simulation shows the relationship between the two variables, that the level of PEC decides the collection rate.
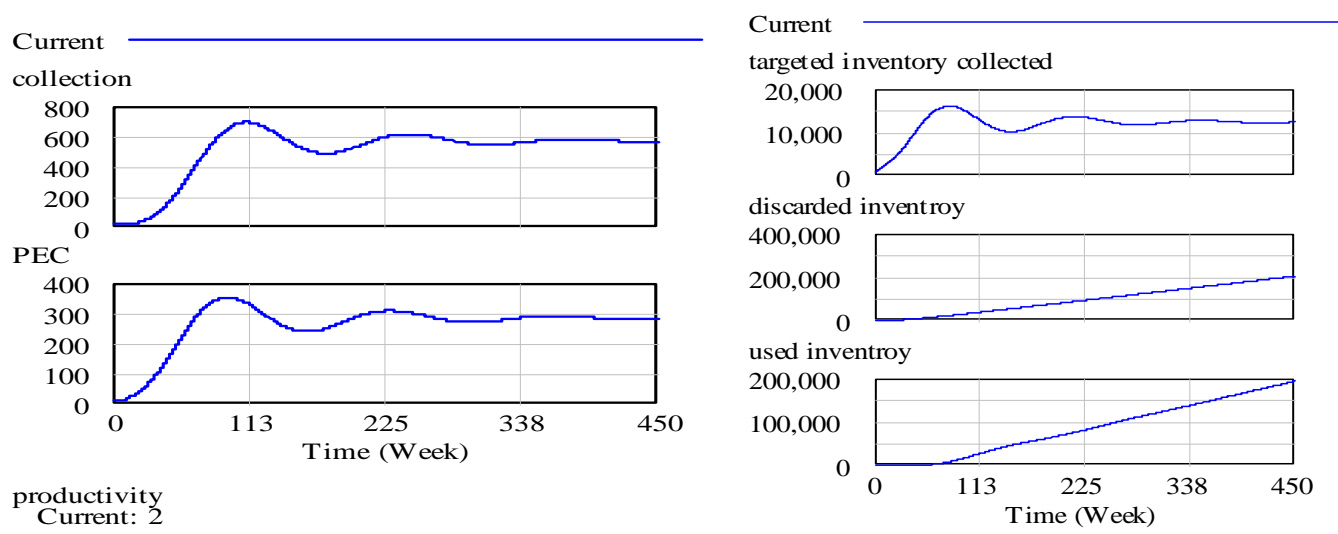

Figure 3(a) The simulation result of a recycling system

Meanwhile Figure 3(b) also shows the same stable tendency of two variables, that they will stabilize at a fixed level. The direct reason can be found at another figure which shows that the targeted level of discarded product inventory tend to be a fix number. Because demand of the remanufactured products as well as out date rate is stable at the end as we discussed above. 


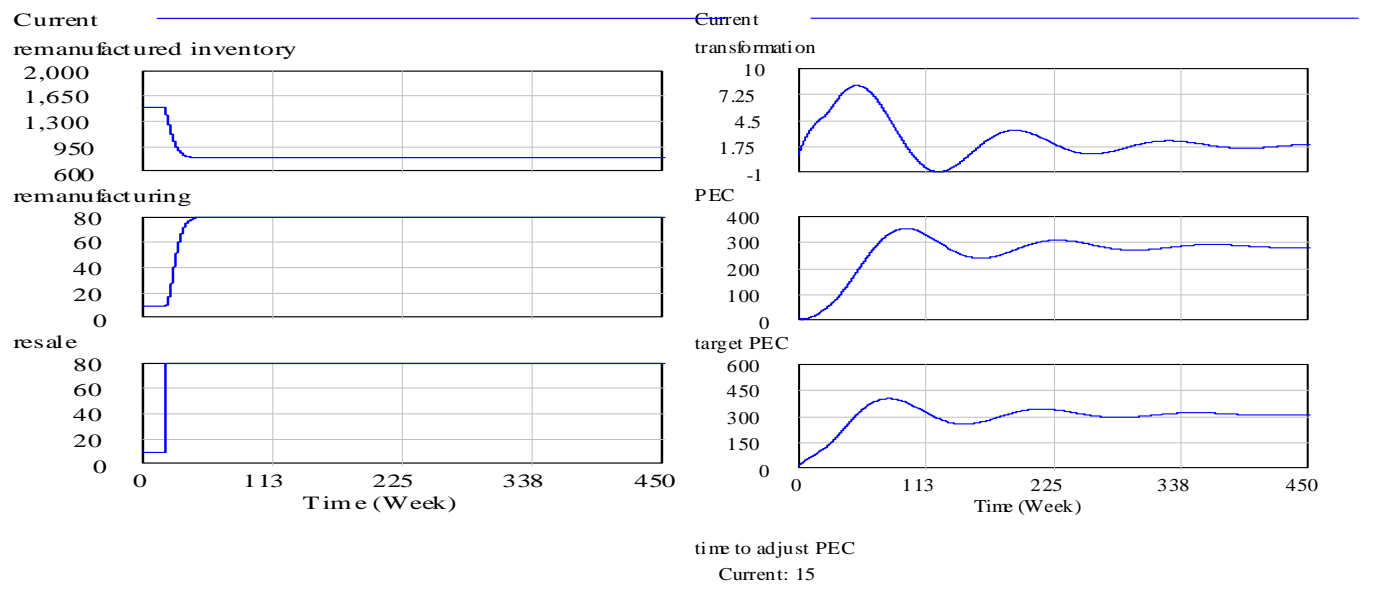

Figure 3(b) the simulation result of a recycling system

\section{B. Resale, remanufacturing and renewed product inventory}

The figure above shows that remanufacturing is subjected to the resale tendency with a postponement. It means remanufacturing companies are droved by the demand of renewed products. While resale reaches a fixed level refurbishing rate follows the same ones. As result the companies will maintain a reasonable number of renewed products in store as safe inventory.

Regarding the essence of customers on environmental consciousness, the relation ship between Transformation, targeted PEC level and actually PEC level is shown above which matches the similar swing tendency of targeted inventory of discarded products.

\section{CONCLUSIONS}

The dynamic recycling system is droved by the a few forces. To identify behaviour rules of the key ones will lead the recycling system to order. Customers' strong environmental consciousness will boost collection rate and resale of discarded products. As a result the demands of remanufactured products will drive the companies to run the recycling business. The study of this paper reminds that it is customers with environmental consciousness who drive the recycling system. And to enactive the recycling system, first and key step is to convert normal people into customer with strong environmental consciousness. They ensure the reasonable collection rate of discarded products and stable demand of remanufactured products.

The model also shows it is a structure and potential function that can be applied to different situation while the constants and variables are changed. It is common that the difference of auxiliary variables and constants is obvious when the model is applied in various products, customer groups under certain regulations. In other words a set of auxiliary variables and constants represents a situation, and definitely there will be different behaviours in the dynamic recycling system. Especially the resale tendency is simplified in this model. To explore a forecast method and include the critical details in the extensive model will be the task in further work.

\section{ACKNOWLEDGMENT}

This paper is supported by the Humanities and Social Science Foundation of Ministry of Education of China (NO. 10YJC630289).

\section{REFERENCE}

[1]M. Fleischman, J.M. Bloemhof-Ruward, R. Dekker, E. van der Laan J.A.E.E. van Nunen, and L.N. van Wassenhove. Quantitative models for reverse logistics: a review. European Journal of Operational Research, 103:1-17, 1997.

[2]V.D.R. Guide, V. Jayaraman, R. Srivastava, and W.C. Benton. Supply-chain management for recoverable manufacturing systems. Interfaces, 30(3):125-142, 2000.

[3]S.M. Gupta and A. Gungor. Issues in environmentally conscious manufacturing and product recovery. Computers and Industrial Engineering, 36(4):811-853, 1999.

[4]R. Dekker, M. Fleischmann, K. Inderfurth, and L.N. van Wassenhove. Reverse Logistics:Quantitative Models for Closed-Loop Supply Chains. Springer-Verlag, Berlin Heidelberg,2004.

[5]Rogers, D., Tibben-Lembke, R., 1998. Going backwards: Reverse logistics trends and practices, Center of Logistics Management, University of Nevada, Reno, USA.

[6]E. Sprow. The mechanics of remanufacture. Manufacturing Engineering, pages 38-45, 1992.

[7]K. Richter and M. Sombrutzki. Remanufacturing planning for the reverse wagner /whitin models. European Journal of Operational Research, 121:304-315, 2000.

[8]Patroklos Georgiadis , Dimitrios Vlachos, The effect of environmental parameters on product recovery,European Journal of Operational Research 157 (2004) 449-464

[9]Taylor, H., 1999. Modeling paper material flows and recycling in the US Macroeconomy, Ph.D. Thesis, Department of Civil Engineering MIT, Cambridge, MA, unpublished.

[10]J.W. Forrester, Industrial Dynamics, MIT Press, Cambridge, MA, 1961.

[11]R.G. Coyle, Management System Dynamics, Wiley, New York, 1978.

[12]J.D. Sterman, Business Dynamics: Systems Thinking and Modeling for a Complex World, McGraw-Hill, New York, 2000.

[13]D. Towill, Industrial dynamics modeling of supply chains, International Journal of Physical Distribution and Logistics Management 26 (2) (1995) 23-42. 
[14]S. Minegishi, D. Thiel, System dynamics modeling and simulation of a particular food supply chain, SimulationPractice and Theory 8 (2000) 321-339.

[15]Zamudio-Ramirez, P., 1996. The Economics of Automobile Recycling, MS Thesis, MIT, Cambridge, MA.

Xia De received Master and $\mathrm{PhD}$ degree of management science and technology from the Wuhan University of Technology.Jan,2008-Jan,2009, he worked as a visiting research fellow in Warwick Business School, Warwick University ,U.K.
He has published more than 30 papers, and was financed by China Scholarship Council ,Ministry of Education of China and Hubei Province Government, as well as some Cooperation Companies .

Currently he is an associate professor of management science and engineering in Management School, Wuhan University of Technology. His main research interests include supply chain management and company social responsibility (CSR). 